\title{
Goodness-of-fit indices for partial least squares path modeling
}

\author{
Jörg Henseler • Marko Sarstedt
}

Received: 26 November 2010 / Accepted: 20 February 2012 / Published online: 4 March 2012 (C) The Author(s) 2012. This article is published with open access at Springerlink.com

\begin{abstract}
This paper discusses a recent development in partial least squares (PLS) path modeling, namely goodness-of-fit indices. In order to illustrate the behavior of the goodness-of-fit index $(\mathrm{GoF})$ and the relative goodness-of-fit index $\left(\mathrm{GoF}_{\text {rel }}\right)$, we estimate PLS path models with simulated data, and contrast their values with fit indices commonly used in covariance-based structural equation modeling. The simulation shows that the $\mathrm{GoF}$ and the $\mathrm{GoF}_{\text {rel }}$ are not suitable for model validation. However, the GoF can be useful to assess how well a PLS path model can explain different sets of data.
\end{abstract}

Keywords Partial least squares path modeling (PLS) · Goodness-of-fit index (GoF)

\section{JEL Classification C39}

\section{Introduction}

For decades, researchers have applied partial least squares (PLS) path modeling to analyze complex relationships between latent variables. Many fields of research have embraced the specific advantages of PLS path modeling, for instance behavioral sciences (e.g., Bass et al. 2003) as well as many fields of business research, such

\footnotetext{
J. Henseler

Institute for Management Research, Radboud University Nijmegen, PO Box 9108, 6500 HK Nijmegen, The Netherlands

e-mail: j.henseler@fm.ru.nl

M. Sarstedt $(\bowtie)$

Institute for Market-based Management, Munich School of Management,

Ludwig-Maximilians-Universität München, Kaulbachstraße 45, 80539 Munich, Germany

e-mail: sarstedt@bwl.lmu.de
} 
as marketing (e.g., Hair et al. 2012; Henseler et al. 2009), strategy (e.g., Hulland 1999), organization (e.g., Sosik et al. 2009), and management information systems (e.g., Ringle et al. 2012; Chin et al. 2003). PLS path modeling's popularity among scientists and practitioners is due to four genuine advantages: First, PLS path modeling "involves no assumptions about the population or scale of measurement" (Fornell and Bookstein 1982, p. 443). PLS path modeling can thus be used when distributions are highly skewed (Bagozzi and Yi 1994), such as in customer satisfaction studies (Fornell 1995). Wold (1973), who developed PLS path modeling, coined the term "soft modeling" because of PLS' rather soft assumptions. Second, even when having a small sample, PLS path modeling can be used to estimate relationships between latent variables with several indicators (Chin and Newsted 1999). As the PLS path modeling algorithm consists of ordinary least squares regressions for separate subparts of the focal path model, the complexity of the overall model hardly influences sample size requirements. Third, modern easy-to-use PLS path modeling software with graphical user-interfaces, like SmartPLS (Ringle et al. 2005), PLS-Graph (Soft Modeling Inc 1992-2002) or the PLS-PM module of XLSTAT software (Addinsoft SARL 2007-2008), and open packages like semPLS (Monecke and Leisch 2012) have contributed to PLS path modeling's appeal. Fourth, PLS path modeling is preferred over covariance-based structural equation modeling (CBSEM) when improper or non-convergent results are likely (so called heywood cases, c.f. Krijnen et al. 1998; Reinartz et al. 2009), as for instance in more complex models, for which the number of latent and manifest variables is high in relation to the number of observations, and the number of indicators per latent variable is low.

Whereas CBSEM minimizes some distance between an observed covariance matrix and an implied covariance matrix, PLS path modeling maximizes a correlation-based criterion (Hanafi 2007) or tends to maximize a covariance-based criterion (Tenenhaus and Tenenhaus 2011). ${ }^{1}$ CBSEM focuses on providing unbiased model parameter estimates, whereas PLS path modeling produces scores that are optimal in some sense. Therefore, the objectives of both methods are very different. Unlike CBSEM, PLS path modeling does not optimize a unique global scalar function. For a long time, this has prevented the development of an index that could provide the researcher with a global validation of the model, such as $\chi^{2}$ and related measures in CBSEM. The lack of a global scalar function and the consequent lack of global goodness-of-fit measures has long been considered a drawback of PLS path modeling.

As a response to this deficiency, Tenenhaus et al. (2004) proposed the goodness-offit index $(\mathrm{GoF})$, which takes both the measurement and structural models' performance into account. As Tenenhaus et al. (2005, p. 173) point out: "The GoF represents an operational solution to this problem as it may be meant as an index for validating the PLS model globally." The GoF has been presented in several research studies (e.g., Tenenhaus et al. 2004, 2005; Esposito Vinzi et al. 2010a; Chin 2010) and has also been used in empirical PLS path modeling applications (e.g., Sarstedt and Ringle 2010; Duarte and Raposo 2010). Furthermore, Esposito Vinzi et al. (2008) proposed

\footnotetext{
1 Simulations show that regularized generalized canonical correlation analysis give almost the same results as PLS path modeling on usual customer satisfaction data. We thank an anonymous reviewer for sharing this insight.
} 
REBUS-PLS, a response-based segmentation approach to treat unobserved heterogeneity in PLS path modeling, which compares local models based on GoF values in order to identify differences between latent classes. Despite its popularity, the GoF's statistical properties have not yet been examined in depth. Specifically, research has not yet broached the issue of the index's appropriateness for model validation, which is of crucial importance in empirical studies (e.g., Rigdon et al. 2010).

Against this background, this paper contributes to the literature on PLS path modeling by providing a conceptual and empirical assessment of extant goodness-of-fit indices for PLS path modeling. The paper is structured as follows: The next section provides a brief introduction to the PLS path modeling algorithm. The third section presents the goodness-of-fit index $(\mathrm{GoF})$ and the relative $\mathrm{GoF}\left(\mathrm{GoF}_{\text {rel }}\right)$, and discusses several conceptual issues related to them. The following section presents the results of a simulation study to compare the indices' performance with that of traditional CBSEM fit measures. The final section draws conclusions for researchers who are interested in the development and application of PLS path modeling as well as for users of PLS path modeling in general and highlights avenue for future research.

\section{PLS path modeling}

PLS is a family of alternating least squares algorithms, which extend principal component and canonical correlation analysis. The method was designed by Wold (1966, 1974, 1982, 1985a,b, 1989) for the analysis of high dimensional data in a low-structure environment and has undergone various extensions and modifications.

PLS path models are formally defined by two sets of linear equations: the inner model and the outer model. The inner model specifies the relations between unobserved or latent variables, while the outer model specifies the relations between a latent variable and its observed indicators or manifest variables. However, the same termi-

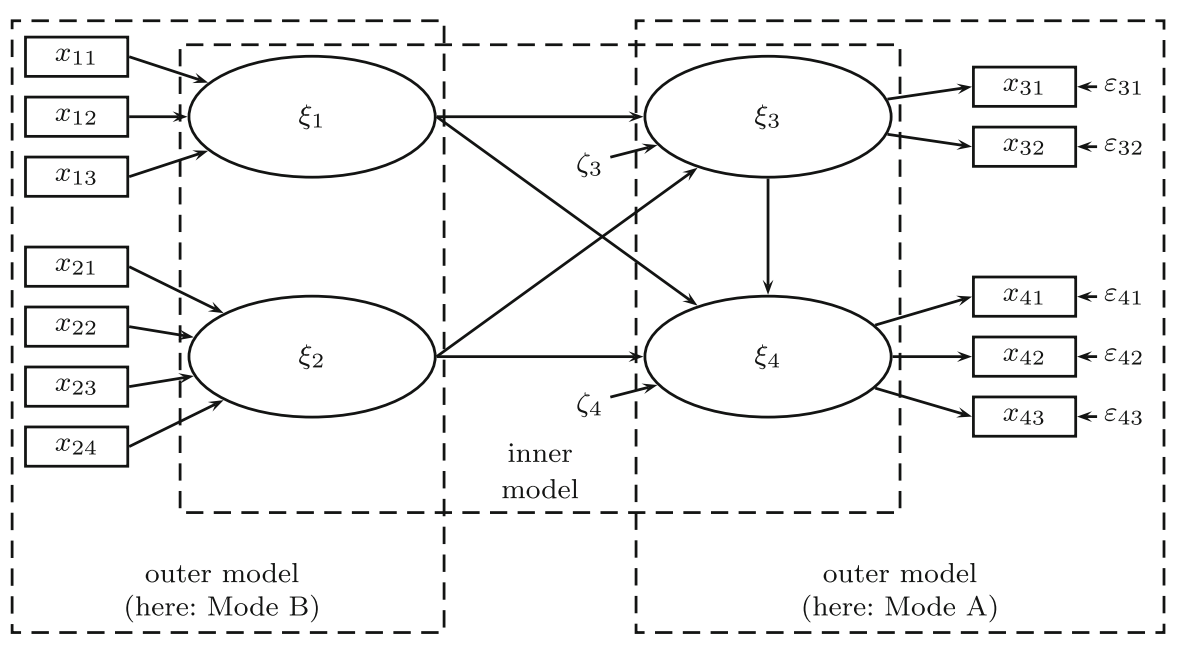

Fig. 1 A simple PLS path model 
nology is not always employed in the literature. For instance, publications addressing CBSEM (e.g., Rigdon 1998) often refer to structural and measurement models or indicator variables, whereas those focusing on PLS path modeling (e.g., Lohmöller 1989) use the terms inner and outer model or manifest variables for similar elements of the cause-effect relationship model. As this paper deals with PLS path modeling, related terminology is used. Figure 1 depicts an example of a PLS path model.

Without a loss of generality, it can be assumed that latent and manifest variables are centered so that the location parameters can be discarded in the following equations. The inner model for relationships between latent variables can be written as:

$$
\Xi=\Xi B+Z,
$$

where $\Xi$ is the vector of latent variables, $B$ denotes the matrix of path coefficients, and $Z$ represents the inner model residuals. The basic PLS design assumes a recursive inner model ${ }^{2}$ that is subject to predictor specification. Thus, the inner model constitutes a causal chain system (i.e. with uncorrelated residuals and without correlations between the residual term of a particular endogenous latent variable and its predictor variables). Predictor specification reduces Eq. 1 to:

$$
\mathrm{E}(\Xi \mid \Xi)=\Xi B
$$

PLS path modeling includes two different modes of outer models: Mode A and Mode B. PLS path modeling with Mode B optimizes a correlation criterion (Hanafi 2007), and PLS path modeling with Mode A tends to optimize a covariance criterion (Tenenhaus and Tenenhaus 2011). A small modification of the PLS algorithm is needed to actually maximize a covariance criterion, but simulations show that both approaches are in very close correspondence (Tenenhaus and Tenenhaus 2011). The choice of a certain mode is subject to statistical and theoretical reasoning, and typically results from a decision to define an outer model as reflective or formative (Fornell and Bookstein 1982).

Model estimation occurs via a sequence of regressions in terms of weight vectors which satisfy the fixed point equations upon convergence. Dijkstra $(1981,2010)$ provides a general analysis of such equations and ensuing convergence issues. Wold's (1982) basic PLS path modeling algorithm, which was later extended by Lohmöller (1989), includes the following three stages: (1) the iterative approximation of latent variable scores, (2) the estimation of outer weights, outer loadings, and path coefficients, and (3) the estimation of location parameters. Only the first stage is iterative and comprises four steps:

Step \#1: Outer approximation of the latent variable scores. Outer proxies of the latent variables, $\hat{\xi}_{j}^{o}$, with zero mean and unit variance, are calculated as linear combinations of their respective indicators. The weights of the linear

\footnotetext{
2 If the centroid or the factorial schemes are used, the iterative PLS algorithm does not require the inner model to be recursive. Feedback loops are thus permitted, and the PLS model is not limited to a causal chain. We thank an anonymous reviewer for this remark.
} 
combinations result from Step \#4 of the previous iteration. Upon initialization, weights are typically set to 1 .

Step \#2: Estimation of the inner weights. Inner weights are calculated for each latent variable in order to reflect how strongly the other latent variables are connected to it. There are three schemes available for determining the inner weights: the centroid, the factorial and the path weighting schemes. To ensure convergence, it is recommended to use the centroid weighting scheme (Henseler 2010), which sets the weights equal to the signs of the correlations between interconnected latent variables. Tenenhaus et al. (2005) provide a more detailed description of the weighting schemes. Regardless of the weighting scheme, a weight of zero is assigned to all non-adjacent latent variables.

Step \#3: Inner approximation of the latent variable scores. Using the afore-determined inner weights, inner proxies of the latent variables, $\hat{\xi}_{j}^{i}$, are calculated as linear combinations of the outer proxies of their respective adjacent latent variables.

Step \#4: Estimation of the outer weights. The outer weights are calculated either as the covariance between the inner proxy of each latent variable and its indicators (in Mode A), or as the regression weights resulting from the ordinary least squares' regression of the inner proxy of each latent variable on its indicators (in Mode B, formative).

These four steps are repeated until the change in the outer weights between two iterations drops below a predefined limit. The algorithm terminates after Step \#1, delivering latent variable scores for all latent variables. Given the constructed indices, loadings and inner regression coefficients are then easily calculated. In order to determine the path coefficients, a (multiple) linear regression is conducted in respect of each endogenous latent variable. The endogenous variable's scores are regressed on the latent predictor variable scores.

\section{Goodness-of-fit indices for PLS path modeling}

\subsection{The goodness-of-fit index $(\mathrm{GoF})$}

Tenenhaus et al. (2004) propose the GoF as a means to validate a PLS path model globally. Specifically, the GoF is defined as follows (Esposito Vinzi et al. 2008):

$$
\mathrm{GoF}=\sqrt{\frac{\sum_{j=1}^{J} \sum_{q=1}^{p_{j}} \operatorname{Cor}^{2}\left(x_{q j}, \hat{\xi}_{j}\right)}{\sum_{j=1}^{J} p_{j}} \times \frac{\sum_{j^{*}=1}^{J^{*}} R^{2}\left(\hat{\xi}_{j^{*}},\left\{\hat{\xi}_{j^{\prime}} \text { s explaining } \hat{\xi}_{j^{*}}\right\}\right)}{J^{*}}} .
$$

In this equation, $J$ is the number of latent variables in the model, and $J^{*}<J$ is the number of endogenous latent variables in the model. $\operatorname{Cor}\left(x_{q j}, \hat{\xi}_{j}\right)$ is the correlation between the $q$ th reflective indicator of the $j$ th latent variable and the corresponding latent variable scores. $R^{2}\left(\hat{\xi}_{j^{*}},\left\{\hat{\xi}_{j}{ }^{\prime}\right.\right.$ s explaining $\left.\left.\hat{\xi}_{j^{*}}\right\}\right)$ is the $R^{2}$ value of the regression that links the $j^{*}$ th endogenous latent variable to its explanatory latent 
variables. Esposito Vinzi et al. (2008, p. 444) provide the following perspective on the GoF:

The left term of the product [...] can be considered as an index measuring the predictive performance of the measurement models: the communality index. It is obtained as the mean of the squared correlations linking each manifest variable $\left(x_{q j}\right)$ to the corresponding latent variable $\left(\hat{\xi}_{j}\right)$ over all blocks. The term on the right side of the product, the average $R^{2}$, is instead an index measuring the predictive performance of the structural model.

Based on this explanation, the GoF can be understood as the geometric mean of two types of $R^{2}$ values' averages: the average communality, $\oslash \mathrm{Com}$, i.e. the average proportion of variance explained when regressing the reflective indicators on their latent variables (Fornell and Larcker 1981), and $\oslash R_{\text {inner }}^{2}$, i. e. the average $R^{2}$ of the endogenous latent variables. The formula for the GoF can thus be rewritten as:

$$
\mathrm{GoF}=\sqrt{\oslash \mathrm{Com} \times \oslash R_{\text {inner }}^{2}}
$$

The GoF as defined by Eq. 3 cannot be applied to PLS path models without endogenous latent variables, because the denominator $J^{*}$ in the right part of Eq. 3 would be zero. Therefore, when the blocks are not connected (i.e., there is no endogenous latent variable), the GoF is defined as $\sqrt{\oslash \mathrm{Com}}$. Consequently, for any structural equation model, the GoF is maximum when the blocks are not connected. ${ }^{3}$

While initially appealing, especially since it is easy to interpret, the GoF also exhibits some limitations.

Being partly based on average communalities, the GoF is conceptually inappropriate whenever measurement models are formative. In such situations, however, PLS path modeling presents itself as favorable compared to CBSEM (Hair et al. 2012). Although it is possible to calculate communalities even for formative indicators (c.f. Esposito Vinzi et al. 2010b), one should note that PLS path models do not intend to explain formative indicators. Consequently, the application and interpretation of the GoF for models involving formative measurement cannot be universally recommended.

In addition, changing from multi-item to single-item measurement would typically increase the GoF, although it usually does not imply an increase in reliability or predictive validity. In order to solve this problem, Esposito Vinzi et al. (2010b) propose to only include latent variables with multi-item measurement into the calculation of the GoF. The ratio behind this redefinition of the GoF is that single-item measurement always implies a communality of one, which means that it does not permit to quantify the measurement error in the indicator. Since the communality in case of single-item measurement is not informative about validity, it should not be considered when calculating the GoF.

Lastly, when exploring different model set-ups, researchers may be tempted to add structural model relations in an effort to increase the $R^{2}$ of one or more endogenous

\footnotetext{
3 We thank an anonymous reviewer for this comment.
} 
latent variables and, ultimately, the GoF. In its current form, however, the GoF does not penalize overparametrization efforts. Consequently, a penalty term similar to the adjusted $R^{2}$ vis-à-vis the regular $R^{2}$ in regression analysis would be needed. Despite this, it is, however, important to note that PLS path modeling should not be considered an entirely exploratory technique; it is up to the researcher to balance PLS path modeling's exploratory spirit and the a priori knowledge about relations in the path model.

\subsection{The Relative GoF $\left(\mathrm{GoF}_{\text {rel }}\right)$}

Recently, Esposito Vinzi et al. (2010b) introduced a normalized version of the GoF, the so-called relative $\mathrm{GoF}\left(\mathrm{GoF}_{\text {rel }}\right)$. $\mathrm{GoF}_{\text {rel }}$ contrasts the communalities obtained from PLS with the communalities obtained from a principal component analysis, and the $\mathrm{R}^{2}$ values obtained from PLS with the $\mathrm{R}^{2}$ values obtained from a canonical correlation analysis (for a motivation of $\mathrm{GoF}_{\text {rel }}$ as well as a more detailed explanation of it, see Esposito Vinzi et al. 2010b). The formula for the $\mathrm{GoF}_{\text {rel }}$ can be written as:

$$
\mathrm{GoF}_{\mathrm{rel}}=\sqrt{\oslash \frac{\mathrm{Com}_{\mathrm{PLS}}}{\mathrm{Com}_{\mathrm{PCA}}} \times \oslash \frac{R_{\mathrm{PLS}}^{2}}{R_{\mathrm{CanCor}}^{2}}} .
$$

When the blocks are not connected (i.e., there is no endogenous latent variable), the $\mathrm{GoF}_{\text {rel }}$ is equal to 1 . In principle, the limitations of the GoF identified in the previous subsection also apply to the relative GoF.

\section{Fit in PLS path modeling versus fit in CBSEM}

\subsection{Conceptual differences}

It is important to recognize that the term "fit" has different meanings in the contexts of CBSEM and PLS path modeling. Fit statistics for CBSEM are derived from the discrepancy between the empirical and the model-implied (theoretical) covariance matrix (Bollen 1989b). In contrast, the GoF focuses on the discrepancy between the observed (in the case of manifest variables) or approximated (in the case of latent variables) values of the dependent variables and the values predicted by the model in question. Owing to the different meanings of fit, there may be instances in which the CBSEM fit statistics indicate a perfect fit, but the GoF signals the absence of fit.

Figure 2 shows an example of CBSEM and PLS path modeling revealing quite different fit statistics. The model consists of two latent variables: a formative exogenous latent variable $\xi$ measured by the indicators $x_{1}$ and $x_{2}$, and a reflective endogenous latent variable $\eta$ measured by the five indicators $y_{1}$ to $y_{5}$. The empirical correlation matrix is shown at the top of the figure. Given the model as specified, CBSEM will be able to generate an implied correlation matrix equal to the empirical correlation matrix. 
Correlation matrix:

\begin{tabular}{r|rrrrrrr} 
& $x_{1}$ & $x_{2}$ & $y_{1}$ & $y_{2}$ & $y_{3}$ & $y_{4}$ & $y_{5}$ \\
\hline$x_{1}$ & 1.0 & 0.0 & 0.0 & 0.0 & 0.0 & 0.0 & 0.0 \\
$x_{2}$ & 0.0 & 1.0 & 0.0 & 0.0 & 0.0 & 0.0 & 0.0 \\
$y_{1}$ & 0.0 & 0.0 & 1.0 & 0.5 & 0.5 & 0.5 & 0.5 \\
$y_{2}$ & 0.0 & 0.0 & 0.5 & 1.0 & 0.5 & 0.5 & 0.5 \\
$y_{3}$ & 0.0 & 0.0 & 0.5 & 0.5 & 1.0 & 0.5 & 0.5 \\
$y_{4}$ & 0.0 & 0.0 & 0.5 & 0.5 & 0.5 & 1.0 & 0.5 \\
$y_{5}$ & 0.0 & 0.0 & 0.5 & 0.5 & 0.5 & 0.5 & 1.0
\end{tabular}

Estimated model:

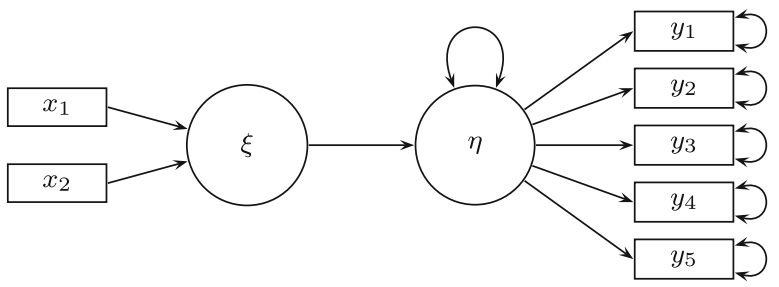

Fig. 2 Example of a situation in which CBSEM and PLS path modeling provide fit statistics with opposite meanings

This means that CBSEM will indicate perfect fit. In contrast, PLS path modeling will yield a GoF value of $0 .{ }^{4}$ Thus, the GoF indicates a lack of fit.

Evidently, PLS path modeling and CBSEM have two different aims: CBSEM aims at estimating parameters such that the empirical and the model-implied covariance matrices are as "close" as possible to oneanother, while PLS path modeling aims at maximizing "explained variability" between variables (manifest or latent) in term of correlation (Mode B) or covariance (Mode A). The different conceptions of fit align with the different principal objectives of CBSEM and PLS path modeling. That is, whereas CBSEM is the method of choice for theory-testing, PLS path modeling is primarily prediction-oriented (Fornell and Bookstein 1982).

\subsection{Empirical comparison between the fit statistics of PLS path modeling and CBSEM}

In order to create a deeper understanding of the $\mathrm{GoF}$ and the $\mathrm{GoF}_{\text {rel }}$ and to assess their adequacy for model validation, we empirically examine their behavior by exposing them to simulated data. We define a well-behaved population model, as depicted in Fig. 3. The population model, which includes a mediating effect, was selected based on the recommendation of Paxton et al. (2001). It has several characteristics that make it particularly useful for our purpose:

- The model has two significant effects: one between an exogenous and an endogenous latent variable, and one between two endogenous latent variables. Thereby we can examine whether a fit measure consistently suggests including those effects.

\footnotetext{
4 PLS path modeling estimates communalities of 0.4 for all five reflective indicators. Since $x_{1}$ and $x_{2}$ do not share any variance with $y_{1}$ to $y_{5}$, the $R^{2}$ value of $\eta$ is 0 , which implies that the GoF is also 0 .
} 


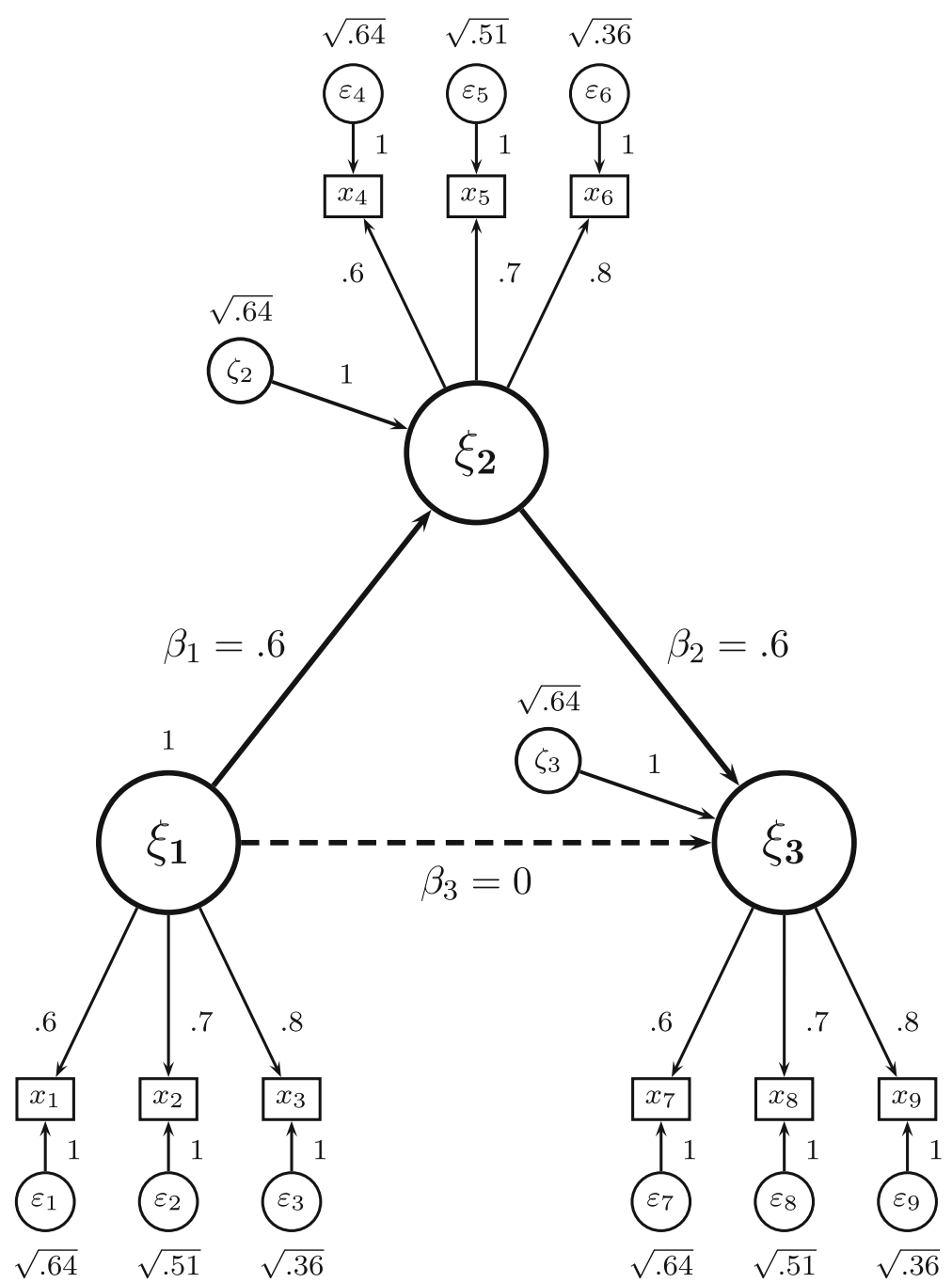

Fig. 3 Population model for the simulated data containing variances and regression weights

- The model has one effect of zero. Thereby we can examine whether a fit measure suggests excluding this effect.

- Finally, the model is the most parsimonious constellation to achieve the above characteristics.

The values in the figure denote standardized population parameters. The exogenous variable $\xi_{1}$, the structural model disturbance terms $\zeta_{2}$ and $\zeta_{3}$, as well as the measurement errors $\varepsilon_{1}$ to $\varepsilon_{9}$ are orthogonal, normally distributed random variables. We generated a data set of 100 observations, which is sufficient to achieve a positivedefinite correlation matrix. The correlation matrix is shown in Table 2 (Appendix).

Table 1 depicts the eight estimated models. Both Models 1 and 4 reflect the population model; Model 4 is more parsimonious. For the PLS path modeling calculations, 


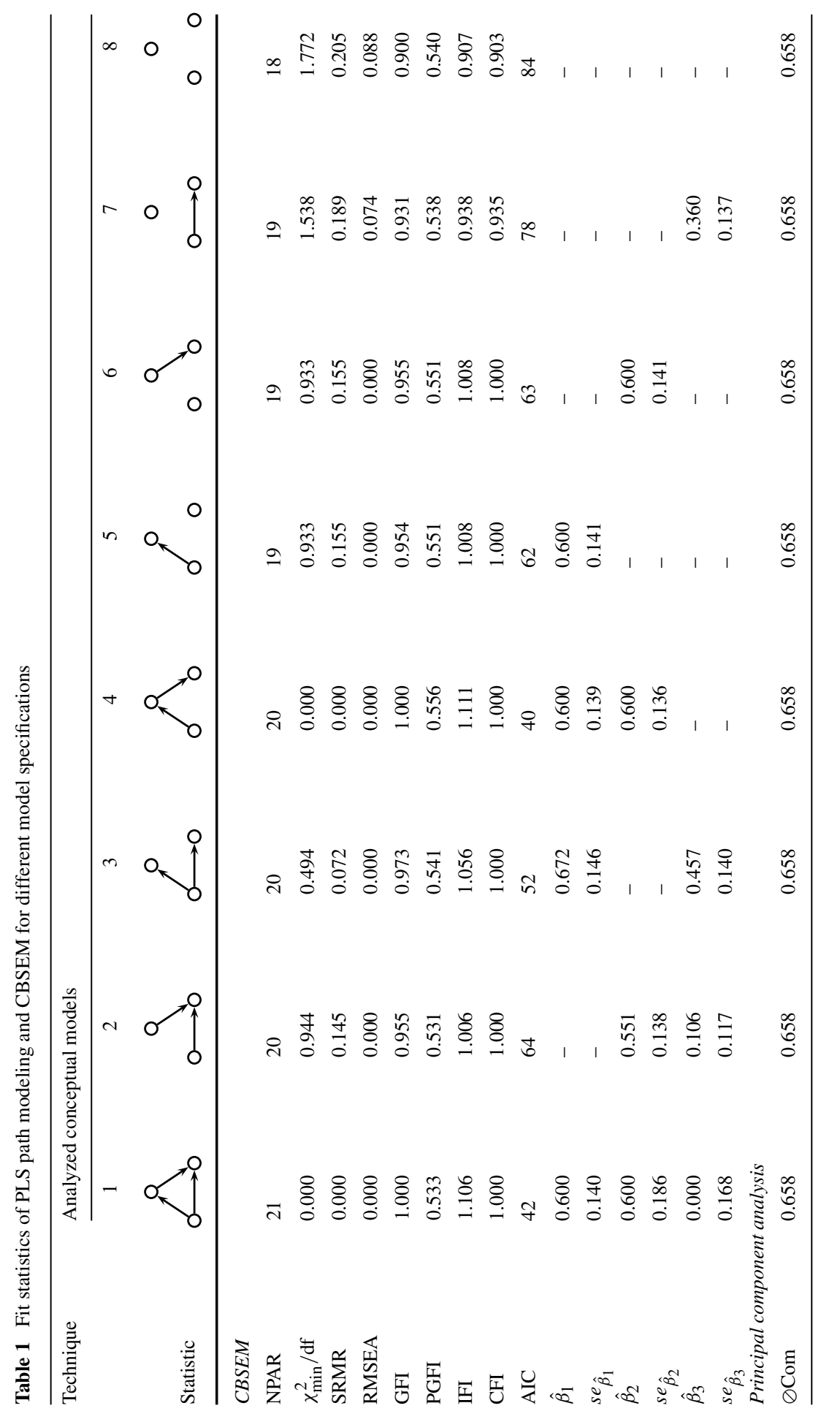




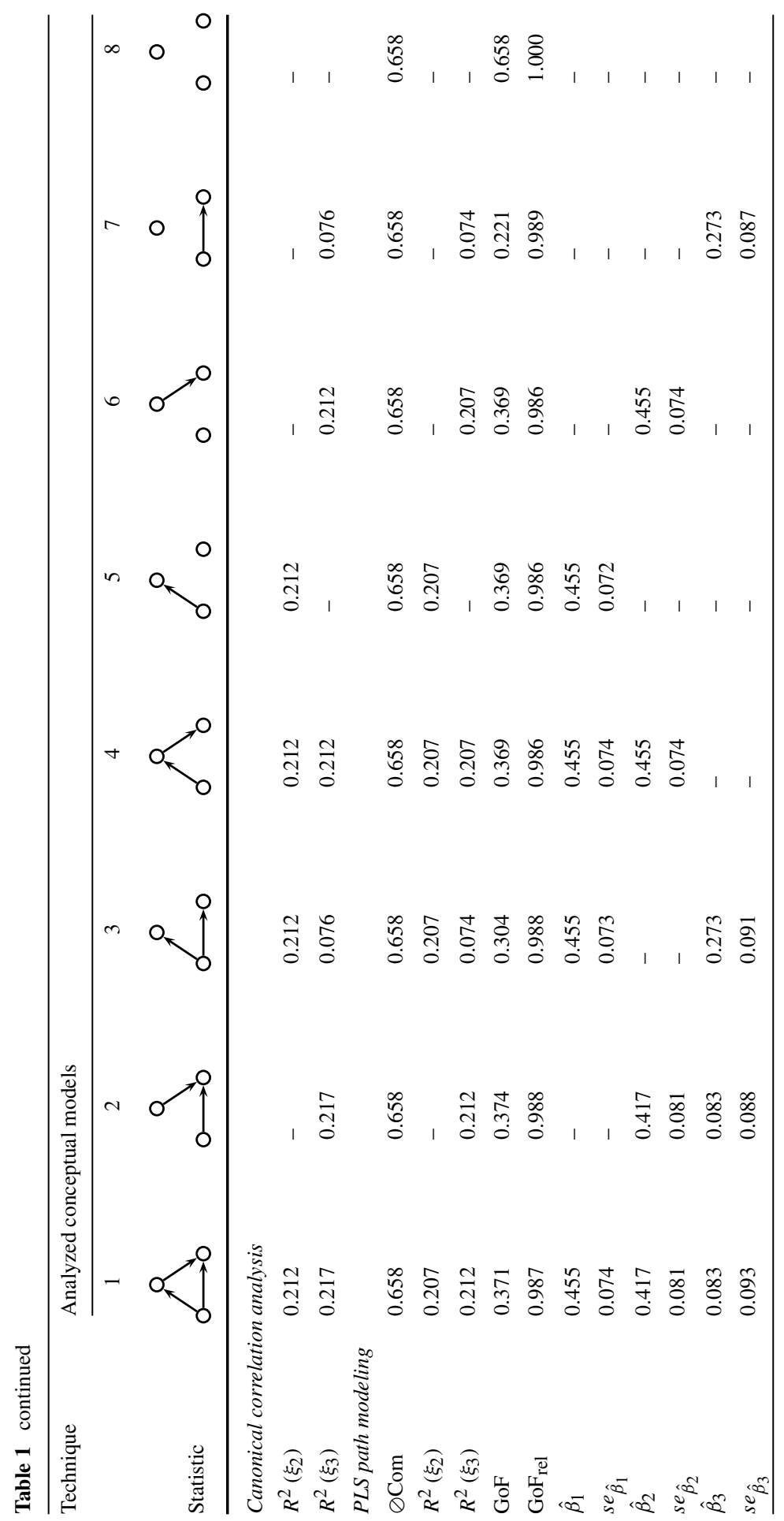


SmartPLS 2.0 M3 beta (Ringle et al. 2005) was used, and the path weighting scheme was applied. In order to estimate Models 5-7, two separate PLS path models per conceptual model were estimated. Model 8 even required three separate PLS path models to be estimated, which in this case were equal to three principal component analyses. The CBSEM calculations were done with AMOS 5, Build 5138 (Arbuckle 2003). The number of distinct parameters (NPAR) ranges from 21 for the most complex model (Model 1) to 18 for the simplest model without any path coefficients (Model 8).

For CBSEM, AMOS determined a variety of popular absolute and relative fit indices. These include: the relative $\chi^{2}\left(\chi_{\min }^{2} / \mathrm{df}\right.$; Wheaton et al. 1977), the standardized root mean square residual (SRMR; Hu and Bentler 1999), the root mean square error of approximation (RMSEA; Steiger 1990), the goodness-of-fit index (GFI; Jöreskog and Sörbom 1986), the parsimony goodness-of-fit index (PGFI; Mulaik et al. 1989), the incremental fit index (IFI; Bollen 1989a), the comparative fit index (CFI; Bentler 1990), as well as Akaike's information criterion (AIC; Akaike 1987).

For PLS path modeling, the GoF and the GoF rel were calculated. Table 1 also shows the average communality ( $\oslash \mathrm{Com}$ ) and the average $R^{2}$ values of the endogenous latent variables $\left(\oslash R_{\text {inner }}^{2}\right)$ as provided by PLS path modeling, so that one can easily verify the correct calculation of the GoF. We also report the results of principal component analyses and canonical correlation analyses in order to facilitate the calculation of the GoF rel.

As Table 1 shows, almost all CBSEM fit measures can discriminate between acceptable models (Models 1 and 4) and unacceptable models (exceptions are CFI and RMSEA). However, only PGFI, IFI, and Akaike's information criterion were able to prioritize the more parsimonious model (Model 4). Using these fit measures, every researcher trained in CBSEM would opt for either Model 1 or Model 4 as the most valid model. Given that Model 4 is more parsimonious than Model 1, researchers are most likely to favor Model 4.

However, for PLS path modeling, the GoF and the $\mathrm{GoF}_{\text {rel }}$ provide a surprising picture. Neither the GoF nor the $\mathrm{GoF}_{\text {rel }}$ provide a good indication for the acceptable models.

Models 1, 2, 4, 5 and 6 all have relatively high GoF values, with Model 2 having the highest GoF. Since all eight models have very similar average communalities, the differences in GoF values can be traced back to the $R^{2}$ values of the inner model. Model 2 has only one endogenous latent variable being explained by two exogenous latent variables. In this way, Model 2 yields the highest (average) $R_{\text {inner }}^{2}$ value among all models. Contrasting the results of Model 1 with those of the remaining models shows that reducing the number of endogenous variables so that only the endogenous latent variable with the highest $R^{2}$ value remains is an effective means to increase the GoF. This behavior of the GoF might work as an incentive for researchers to streamline models accordingly, and to focus on a single endogenous latent variable - whether this comes close to the true population model or not.

Despite the substantial differences between the eight models, the $\mathrm{GoF}_{\text {rel }}$ provides very similar values close to one for the first seven models. The $\mathrm{GoF}_{\text {rel }}$ of the eighth model is by Definition 1 . In particular, all $\mathrm{GoF}_{\text {rel }}$ values meet the rule of thumb formulated by Esposito Vinzi et al. (2010b, p. 59) who say that "a value of the relative GoF equal to or higher than 0.9 clearly speaks in favour of the model." If one were 
to interpret the $\mathrm{GoF}_{\text {rel }}$ in a relative manner, one would have to select Model 8 as the model with the highest goodness of fit.

\section{Implications and recommendations}

Originally proposed by Tenenhaus et al. (2004), the GoF has recently gained increasing dissemination as an index to judge the overall model fit in PLS path models. Despite this, prior research has not yet examined the GoF's statistical properties. Researchers making use of PLS path modeling's goodness-of-fit indices should know how to interpret them and for which purposes they can be used. Within this article, we have provided an extensive discussion about the characteristics of the $\mathrm{GoF}$ and the $\mathrm{GoF}_{\text {rel }}$.

Since the GoF has been introduced as a statistical measure of model fit, a presumably natural field of application would be to use it for model validation and model selection. The underlying idea would be that the model with a higher fit is the better or more valid model. However, using simulated data, we have illustrated that the GoF and the $\mathrm{GoF}_{\text {rel }}$ are not suitable for model validation. Neither of these indices is able to separate valid models from invalid models. In fact, researchers would be misled if they chose for the model yielding the highest GoF. Instead, researchers should carefully evaluate the path coefficients and particularly their significance in order to decide upon which paths to leave in the model and which to discard.

For some specific types of model validation, though, the application of the GoF does make sense. That is, when it comes to validating models that differ not in their structure but in their (reflective) indicators, the GoF is the statistic of choice. If the structural model remains constant, the GoF can indirectly assess relative changes in convergence validity as expressed by the average variance extracted (Fornell and Larcker 1981).

The GoF is also very useful for data comparisons (i.e., varying the data while keeping the model constant). As a consequence, the GoF is best applied in group comparisons (Sarstedt et al. 2011) and assessments of unobserved heterogeneity, as it is the case with the REBUS-PLS procedure. In these cases, the GoF can answer questions on how well different subsets of the data can be explained by a particular model.

Our findings also confirm the different objectives of PLS path modeling and CBSEM. While PLS path modeling provides latent variable scores with beneficial characteristics for prediction, CBSEM is better suited for model validation, model selection, and model comparisons. In particular, it has become apparent that whereas CBSEM fit measures can help to determine whether a model is adequate or not, PLS' GoF and $\mathrm{GoF}_{\text {rel }}$ do not provide such information.

In order to increase the GoF's applicability to different types of models, there is a need to redefine the original GoF so that it can be used to assess formative measurement models. For a formative block, one might replace in the GoF formula the block communality by the $R^{2}$ between the inner proxy of the formative block and the block's manifest variables. ${ }^{5}$ Another point of departure could be assessing a formative block's weights. Future research should make more concrete suggestions of how to

\footnotetext{
5 We thank an anonymous reviewer for this suggestion.
} 
improve the GoF, and demonstrate the viability of the improvements by means of both conceptual reasoning and Monte Carlo simulations.

Open Access This article is distributed under the terms of the Creative Commons Attribution License which permits any use, distribution, and reproduction in any medium, provided the original author(s) and the source are credited.

\section{Appendix}

Table 2 Correlation matrix for the simulation model

\begin{tabular}{llllllllll}
\hline & $x_{1}$ & $x_{2}$ & $x_{3}$ & $x_{4}$ & $x_{5}$ & $x_{6}$ & $x_{7}$ & $x_{8}$ & $x_{9}$ \\
\hline$x_{1}$ & 1.0000 & 0.4200 & 0.4800 & 0.2160 & 0.2520 & 0.2880 & 0.1296 & 0.1512 & 0.1728 \\
$x_{2}$ & 0.4200 & 1.0000 & 0.5600 & 0.2520 & 0.2940 & 0.3360 & 0.1512 & 0.1764 & 0.2016 \\
$x_{3}$ & 0.4800 & 0.5600 & 1.0000 & 0.2880 & 0.3360 & 0.3840 & 0.1728 & 0.2016 & 0.2304 \\
$x_{4}$ & 0.2160 & 0.2520 & 0.2880 & 1.0000 & 0.4200 & 0.4800 & 0.2160 & 0.2520 & 0.2880 \\
$x_{5}$ & 0.2520 & 0.2940 & 0.3360 & 0.4200 & 1.0000 & 0.5600 & 0.2520 & 0.2940 & 0.3360 \\
$x_{6}$ & 0.2880 & 0.3360 & 0.3840 & 0.4800 & 0.5600 & 1.0000 & 0.2880 & 0.3360 & 0.3840 \\
$x_{7}$ & 0.1296 & 0.1512 & 0.1728 & 0.2160 & 0.2520 & 0.2880 & 1.0000 & 0.4200 & 0.4800 \\
$x_{8}$ & 0.1512 & 0.1764 & 0.2016 & 0.2520 & 0.2940 & 0.3360 & 0.4200 & 1.0000 & 0.5600 \\
$x_{9}$ & 0.1728 & 0.2016 & 0.2304 & 0.2880 & 0.3360 & 0.3840 & 0.4800 & 0.5600 & 1.0000 \\
\hline
\end{tabular}

\section{References}

Addinsoft SARL (2007-2008) XLSTAT-PLSPM. Paris, France. http://www.xlstat.com/en/products/xlstat$\mathrm{plspm} /$

Akaike H (1987) Factor analysis and AIC. Psychometrika 52(3):317-332

Arbuckle JL (2003) Amos 5 User's Guide. SPSS

Bagozzi RP, Yi Y (1994) Advanced topics in structural equation models. In: Bagozzi RP (ed) Advanced methods of marketing research. Blackwell, Oxford, p 151

Bass B, Avolio B, Jung D, Berson Y (2003) Predicting unit performance by assessing transformational and transactional leadership. J Appl Psychol 88(2):207-218

Bentler PM (1990) Comparative fit indexes in structural models. Psychol Bull 107(2):238-246

Bollen KA (1989a) A new incremental fit index for general structural equation models. Sociol Methods Res 17(3):303

Bollen KA (1989b) Structural equations with latent variables. Wiley, New York, NY

Chin W (2010) How to write up and report PLS analyses. In: EspositoVinzi V, Chin WW, Henseler J, Wang $\mathrm{H}$ (eds) Handbook of partial least squares: concepts, methods and applications. Springer, Heidelberg pp 655-690

Chin WW, Newsted PR (1999) Structural equation modeling analysis with small samples using partial least squares. In: Hoyle RH (ed) Statistical strategies for small sample research. Sage, Thousand Oaks, CA, pp 334-342

Chin WW, Marcolin BL, Newsted PR (2003) A partial least squares latent variable modeling approach for measuring interaction effects. Results from a Monte Carlo simulation study and an electronic-mail emotion/adopion study. Inf Syst Res 14(2):189-217

Dijkstra TK (1981) Latent variables in linear stochastic models: reflections on "Maximum Likelihood" and "Partial Least Squares" methods. PhD thesis, Groningen University, Groningen, a second edition was published in 1985 by Sociometric Research Foundation 
Dijkstra TK (2010) Latent variables and indices: Herman Wold's basic design and partial least squares. In: Vinzi VE, Chin WW, Henseler J, Wang H (eds) Handbook of partial least squares: concepts, methods, and applications, computational statistics, vol II, Springer, Heidelberg, pp 23-46 (in print)

Duarte P, Raposo M (2010) A PLS model to study brand preference: an application to the mobile phone market. In: EspositoVinzi V, Chin WW, Henseler J, Wang H (eds) Handbook of partial least squares: concepts, methods and applications. Springer, Heidelberg, pp 449-485

EspositoVinzi V, Trinchera L, Squillacciotti S, Tenenhaus M (2008) REBUS-PLS: A response-based procedure for detecting unit segments in PLS path modelling. Appl Stoch Models Bus Ind 24(5):439-458

Esposito Vinzi V, Chin WW, Henseler J, Wang H (eds) (2010a) Handbook of partial least squares: concepts, methods and applications. Springer, Heidelberg

Esposito Vinzi V, Trinchera L, Amato S (2010b) PLS path modeling: from foundations to recent developments and open issues for model assessment and improvement. In: EspositoVinzi V, Chin WW, Henseler J, Wang $\mathrm{H}$ (eds) Handbook of partial least squares: concepts, methods and applications. Springer, Heidelberg, pp 47-82

Fornell C (1995) The quality of economic output: empirical generalizations about its distribution and relationship to market share. Market Sci 14(3):G203-G211

Fornell C, Bookstein FL (1982) Two structural equation models: LISREL and PLS applied to consumer exit-voice theory. J Market Res 19(4):440-452

Fornell C, Larcker DF (1981) Evaluating structural equation models with unobservable variables and measurement error. J Market Res 18(1):39-50

Hair J, Sarstedt M, Ringle C, Mena J (2012) An assessment of the use of partial least squares structural equation modeling in marketing research. J Acad Market Sci (forthcoming)

Hanafi M (2007) PLS path modelling: computation of latent variables with the estimation mode B. Comput Stat 22(2):275-292

Henseler J (2010) On the convergence of the partial least squares path modeling algorithm. Comput Stat 25(1):107-120

Henseler J, Ringle C, Sinkovics R (2009) The use of partial least squares path modeling in international marketing. Adv Int Market 20(2009):277-319

Hu LT, Bentler PM (1999) Cutoff criteria for fit indexes in covariance structure analysis: conventional criteria versus new alternatives. Struct Equ Model 6(1):1-55

Hulland J (1999) Use of partial least squares (PLS) in strategic management research: a review of four recent studies. Strateg Manag J 20(2):195-204

Jöreskog KG, Sörbom D (1986) LISREL VI: Analysis of linear structural relationships by maximum likelihood and least squares methods. Scientific Software, Mooresville, IN

Krijnen W, Dijkstra T, Gill R (1998) Conditions for factor (in) determinacy in factor analysis. Psychometrika 63(4):359-367

Lohmöller JB (1989) Latent variable path modeling with partial least squares. Physica, Heidelberg

Monecke A, Leisch F (2012) semPLS: Structural equation modeling using partial least squares. J Stat Softw (forthcoming)

Mulaik SA, James LR, van Alstine J, Bennett N, Lind S, Stilwell CD (1989) Evaluation of goodness-of-fit indices for structural equation models. Psychol Bull 105:430-445

Paxton P, Curran P, Bollen K, Kirby J, Chen F (2001) Monte carlo experiments: design and implementation. Struct Equ Model 8(2):287-312

Reinartz WJ, Haenlein M, Henseler J (2009) An empirical comparison of the efficacy of covariance-based and variance-based SEM. Int J Res Market 26(4):332-344

Rigdon EE (1998) Structural equation modeling. In: Marcoulides GA (ed) Modern methods for business research, Lawrence Erlbaum Associates. Mahwah, pp 251-294

Rigdon EE, Ringle CM, Sarstedt M (2010) Structural modeling of heterogeneous data with partial least squares. In: Malhotra NK (ed) Review of marketing research, vol 7. Sharpe, pp 255-296

Ringle C, Sarstedt M, Straub D (2012) A critical look at the use of pls-sem in mis quarterly. MIS Q 36(1): iii-xiv

Ringle CM, Wende S, Will A (2005) SmartPLS 2.0 M3. University of Hamburg, Hamburg, Germany. http://www.smartpls.de

Sarstedt M, Ringle CM (2010) Treating unobserved heterogeneity in PLS path modelling: a comparison of FIMIX-PLS with different data analysis strategies. J Appl Stat 37(8):1299-1318

Sarstedt M, Henseler J, Ringle CM (2011) Multigroup analysis in partial least squares (PLS) path modeling: Alternative methods and empirical results. Adv Int Market 22:195-218 
Soft Modeling, Inc (1992-2002) PLS-Graph Version 3.0. Houston, TX. http://www.plsgraph.com Sosik J, Kahai S, Piovoso M (2009) Silver bullet or voodoo statistics. Group Organ Manag 34(1):5

Steiger JH (1990) Structural model evaluation and modification: an interval estimation approach. Multivar Behav Res 25(2):173-180

Tenenhaus A, Tenenhaus M (2011) Regularized generalized caconical correlation analysis. Psychometrika 76(2):257-284

Tenenhaus M, Amato S, Esposito Vinzi V (2004) A global goodness-of-fit index for PLS structural equation modelling. In: Proceedings of the XLII SIS scientific meeting. pp 739-742

Tenenhaus M, Vinzi VE, Chatelin YM, Lauro C (2005) PLS path modeling. Comput Stat Data Anal 48(1):159-205

Wheaton B, Muthén B, Alwin DF, Summers GF (1977) Assessing reliability and stability in panel models. In: Heise D (ed) Sociological methodology. Jossey-Bass, Washington, DC, pp 84-136

Wold HOA (1966) Non-linear estimation by iterative least squares procedures. In: David FN (ed) Research papers in statistics. Wiley, London, pp 411-444

Wold HOA (1973) Nonlinear iterative partial least squares (NIPALS) modelling. Some current developments. In: Krishnaiah PR (ed) Proceedings of the 3rd international symposium on multivariate analysis, Dayton, OH. pp 383-407

Wold HOA (1974) Causal flows with latent variables: partings of the ways in the light of NIPALS modelling. Eur Econ Rev 5(1):67-86

Wold HOA (1982) Soft modelling: the basic design and some extensions. In: Jöreskog KG, Wold HOA (eds) Systems under indirect observation. Causality, structure, prediction, vol II. North-Holland, Amsterdam, New York, Oxford, pp 1-54

Wold HOA (1985a) Partial least squares. In: Kotz S, Johnson NL (eds) Encyclopaedia of statistical sciences, vol 6. Wiley, New York, NY, pp 581-591

Wold HOA (1985b) Partial least squares and LISREL models. In: Nijkamp P, Leitner H, Wrigley N (eds) Measuring the unmeasurable. Nijhoff, Dordrecht, Boston, Lancaster, pp 220-251

Wold HOA (1989) Introduction to the second generation of multivariate analysis. In: Wold HOA (ed) Theoretical empiricism. A general rationale for scientific model-building. Paragon House, New York, pp VIII-XL 